\title{
Performance of a revised capnodynamic method during lung injury
}

Thorir Svavar Sigmundsson ${ }^{1,2}$, Tomas Öhman ${ }^{1,2}$, Magnus Hallbäck ${ }^{3}$, Fernando Suarez Sipmann, ${ }^{4,5}$ Håkan Björne ${ }^{1,2}$, Caroline Hällsjö Sander1,2

${ }^{1}$ Department of Perioperative Medicine and Intensive Care, Karolinska University Hospital, Solna, Sweden, ${ }^{2}$ Department of Physiology and Pharmacology, Karolinska Institutet, Stockholm, Sweden, ${ }^{3}$ Maquet Critical Care AB, Solna, Sweden, ${ }^{4}$ Department of Surgical Sciences, Section of Anaesthesiology and Critical Care, Hedenstierna's laboratory, Uppsala University, Uppsala, Sweden, ${ }^{5} \mathrm{CIBER}$ de Enfermedades Respiratorias, Instituto de Salud Carlos III, Madrid, Spain.

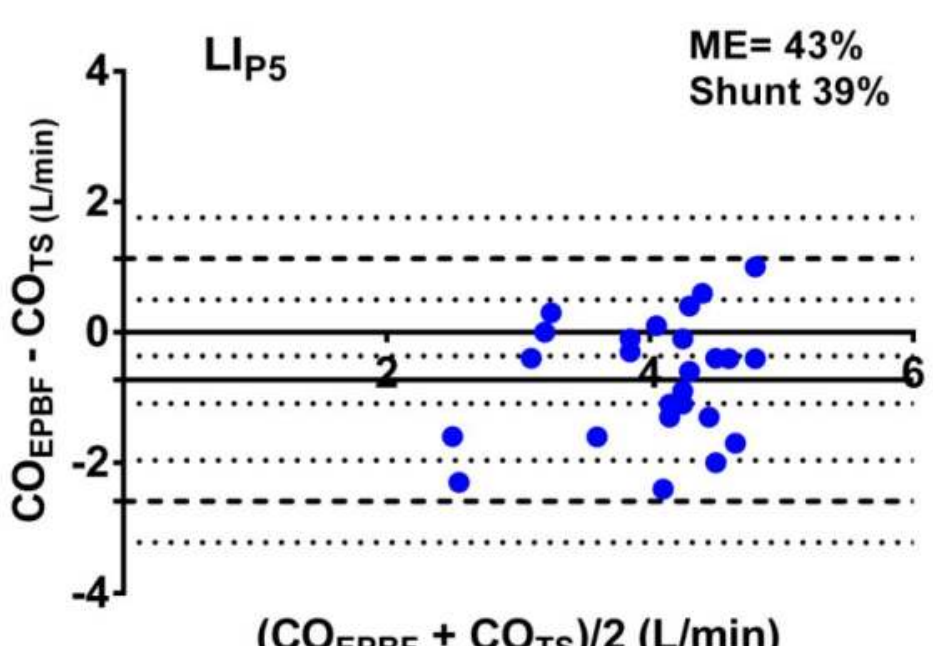

$\left(\mathrm{CO}_{\mathrm{EPBF}}+\mathrm{CO}_{\mathrm{TS}}\right) / 2(\mathrm{~L} / \mathrm{min})$

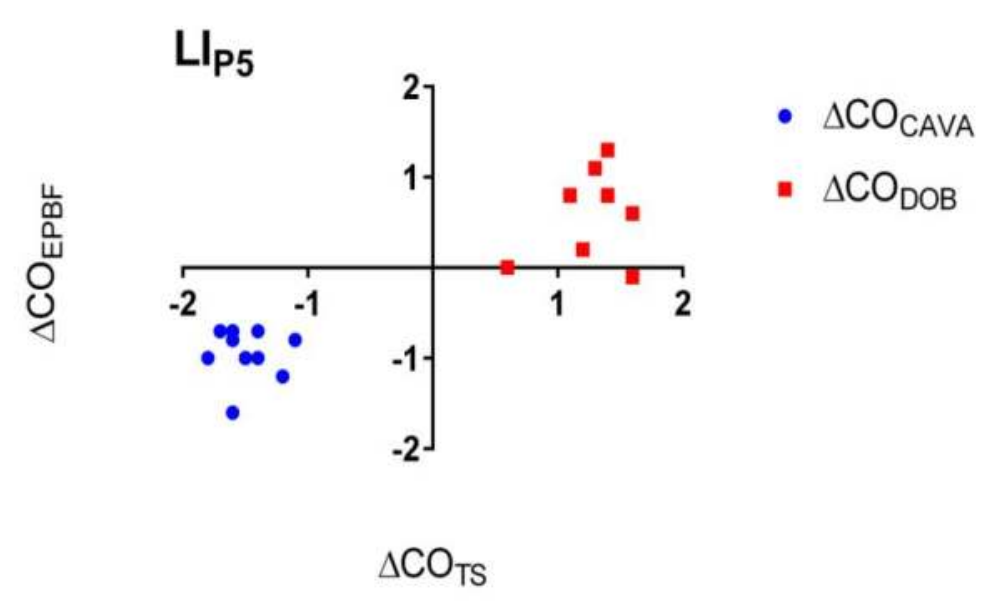

\section{Introduction}

A capnodynamic method effectively calculates pulmonary blood flow ( $\left.\mathrm{CO}_{\mathrm{EPBF}}\right)$ using an automatic hold in three out of nine breaths during mechanical ventilation. In a previous study, the performance of the capnodynamic method was affected during lung injury (LI) when using inspiratory holds ${ }^{1}$. Revision of the method with expiratory holds inserted into the breathing pattern has shown better performance during hemodynamic changes in normal lungs with low shunt fraction ${ }^{2}$. The aim of the current study was to evaluate the revised $\mathrm{CO}_{\mathrm{EPBF}}$ during acute lung injury with high shunt fractions.

\section{Methods}

Ten pigs were submitted to severe LI with lavage and subsequent ventilator induced lung injury. Effective pulmonary blood flow was calculated with $\mathrm{CO}_{\text {EPBF }}$ and compared to a reference method for cardiac output, an ultrasonic flow probe placed around the pulmonary artery trunk $\left(\mathrm{CO}_{\mathrm{TS}}\right)$ at (1) baseline with PEEP $5 \mathrm{cmH}_{2} \mathrm{O}$ $\left(\mathrm{BAS}_{\mathrm{P} 5}\right)$, (2) LI with PEEP $5 \mathrm{cmH}_{2} \mathrm{O}\left(\mathrm{LI}_{\mathrm{P} 5}\right)$ and (3) $\mathrm{LI}$ with optimal PEEP (LI POpt), range 10-16 $\mathrm{CmH}_{2} \mathrm{O}$ using an open lung tool recruitment. Cardiac output changes were enforced during steps 2 and 3 to estimate trending.

\section{Results}

Lung injury and PEEP resulted in significant changes in shunt and $\mathrm{PaO}_{2} / \mathrm{FiO}_{2}$ index (PFI). Bias (levels of agreement) changed from 0.5 (0.6 to 1.6$) \mathrm{L} / \mathrm{min}$ and mean error (ME) $30 \%$ at BAS $_{P 5}$ to $-0.7(-2.6$ to 1.2$) \mathrm{L} / \mathrm{min}$ and $\mathrm{ME} 43 \%$ during $\mathrm{LI}_{\mathrm{P} 5}$ and finally $1.3(0.0$ to 2.6$) \mathrm{L} / \mathrm{min}$ and ME $36 \%$ after $\mathrm{LI}_{\text {POpt }}$. Concordance was 89 and $90 \%$ during $\mathrm{LI}_{\mathrm{P} 5}$ and $\mathrm{LI}_{\mathrm{POpt}}$.

\begin{tabular}{|r|c|c|c|c|}
\hline Condition & $\begin{array}{c}\mathrm{CO}_{\text {EPBF }} \\
(\mathrm{L} / \mathrm{min})\end{array}$ & $\begin{array}{c}\mathrm{CO}_{\mathrm{TS}} \\
(\mathrm{L} / \mathrm{min})\end{array}$ & $\begin{array}{c}\text { Shunt } \\
(\%)\end{array}$ & PFI \\
\hline Baseline PEEP 5 & $4.0(0.4)$ & $3.5(0.4)$ & $10(2)$ & $383(48)$ \\
\hline LI PEEP 5 & $3.7(0.8)$ & $4.4(0.7)$ & $39(12)$ & $131(77)$ \\
\hline LI PEEPP 5 CAVA & $2.4(0.7)$ & $2.8(0.5)$ & $31(17)$ & $128(93)$ \\
\hline LI PEEP 5 DOB & $4.6(0.7)$ & $5.8(0.8)$ & $42(8)$ & $137(52)$ \\
\hline LI PEEP Opt & $4.8(0.6)$ & $3.6(0.4)$ & $9(3)$ & $492(59)$ \\
\hline LI PEEP Opt CAVA & $3.5(0.5)$ & $3.5(0.3)$ & $9(4)$ & $475(82)$ \\
\hline LLI PEEPP Opt DOB & $5.9(0.7)$ & $4.7(0.5)$ & $13(6)$ & $471(102)$ \\
\hline
\end{tabular}

\section{Conclusion}

$\mathrm{CO}_{\text {EPBF }}$ performed acceptably during $\mathrm{LI}$ with high shunt fractions using expiratory holds in the breathing pattern and trending remained good. $\mathrm{CO}_{\text {EPBF }}$ could possibly be used in patients with increased shunt for which clinical studies are pending. 